Research Article

\title{
Drug utilization pattern of antidiabetic agents in a tertiary care hospital of western Odisha, India
}

\author{
Ratna Agrawal*, Bhabagrahi Rath, Kaustav Saha, Sabita Mohapatra
}

\begin{abstract}
Department of Pharmacology, V. S. S. Institute of Medical Sciences and Research, Burla, Sambalpur, Odisha, India

Received: 01 August 2016 Accepted: 03 September 2016

*Correspondence to:

Dr. Ratna Agrawal,

Email: ratna.arang@gmail.com
\end{abstract}

Copyright: (C) the author(s), publisher and licensee Medip Academy. This is an openaccess article distributed under the terms of the Creative Commons Attribution NonCommercial License, which permits unrestricted noncommercial use, distribution, and reproduction in any medium, provided the original work is properly cited.

\begin{abstract}
Background: A changing life style in developing countries like India has increased the statistical figure of diabetes mellitus even among rural populations and younger age groups. Prevalence rate of diabetes in Odisha is about $10 \%$. There is intensive polypharmacy as regards the treatment of diabetes mellitus which is not only affecting the quality of life of patients adversely by producing side effects including hypoglycemia but also taking a toll on the financial state of the poor people. With this background, this study was conducted to evaluate the drug utilization pattern of antidiabetic agents to facilitate rational use of drugs in this condition.

Methods: This observational study was conducted in 230 patients for a period of 2 months in the department of general medicine at V. S. S. Institute of Medical Sciences and Research, Burla. After taking informed consent, the patient's case records, prescriptions, investigational reports and co - morbidities were evaluated.

Results: In our study, insulin was found to be the most commonly used antidiabetic agent both during hospital stay $(80 \%)$ and also at the time of discharge (60\%). Metformin with sulfonylurea was the most frequently prescribed oral anti diabetic combination in $9.5 \%$ of patients. Average cost of insulin therapy was rs. 80 per patient per month and of oral antidiabetic drug was rs. 45.66 per patient per month during hospital stay.

Conclusions: The prescribing trend has been monotherapy with insulin followed by oral antidiabetic drugs in the form of glimepiride and metformin combination.
\end{abstract}

Keywords: Defined daily dose, Insulin, Metformin, Sulfonylureas

\section{INTRODUCTION}

Diabetes mellitus is a group of a metabolic diseases characterized by hyperglycemia due to defect of insulin secretion or insulin action or both. The Odisha state comprises of 44 million people and according to estimates, around 1.5 million people in Odisha are suffering from diabetes against the country's 62 million. ${ }^{1-}$

${ }^{4}$ ICMR study showed that $8-12 \%$ population in urban areas and $6-8 \%$ population in rural areas are having diabetic. The most alarming fact is that diabetes has made deep inroads into the most backward, remote and tribal pockets shattering all myths of being the disease of the affluent. Little more than a decade back, diabetes incidence in rural areas was $<1 \%$. At present, India has 61 million diabetics and the trend is expected to continue in the years to come. ${ }^{3}$ So a new National programme of prevention and control of cancer, diabetes, cardiovascular disease and Stroke (NPCDCS) has been started and Odisha along with twenty other states have been enrolled under that on the basis of their backwardness, inaccessibility and poor health indicators. ${ }^{5}$ The focus of programme is on promotion of healthy life style, early diagnosis and management of diabetes, hypertension, cardiovascular and common cancers. A changing life style in developing countries like India has enormously increased the statistical figure of chronic disease like diabetes mellitus. A good glycemic control is the cornerstone of the management of diabetes. Oral anti diabetic agents are the most commonly prescribed drugs for type 2 diabetes. 
The choice of agents largely depends upon:

- A1c reduction required and the ability of the drug to provide the reduction

- Ability to address the components (fasting and post prandial) of glycemia

- Ability to minimize hypoglycemia and weight gain

- Safety in a variety of clinical situations including cardiovascular safety

- Adverse events associated with the drug

- Cost effectiveness of the therapy

Assessing the economic burden of diabetes is challenging because of the complexity involved in identifying the direct and indirect costs of disease. As these patients have several other complications and co-morbidities, the annual cost of diabetes health care rises. The principal aim of drug utilization research is to facilitate rational use of drug in the populations.

Moreover, there are no accepted guidelines for treating type 2 diabetes mellitus in Indian scenario, because all are formulated in western countries. More so, it is necessary to follow a treatment protocol in common comorbidities associated with type 2 diabetes. So we have aimed to study the utilization pattern of drugs used in diabetes mellitus in a tertiary care hospital.

\section{METHODS}

This observational study was conducted in 230 patients for a period of 2 months in the department of general medicine at V. S. S. Institute of Medical Sciences and Research, Burla during period of 15 July 2015 to 15 September 2015.

The patients were taken from the department of medicine. A total of 230 patients were enrolled in the study. Data were collected by direct patient interview and from case records and discharge certificates. Informed consent was obtained from all patients included in the study.

\section{Inclusion criteria}

All cases diagnosed with diabetes mellitus (both type land type 2) admitted in the inpatient department of general medicine ward.

\section{Exclusion criteria}

Patients with gestational diabetes were excluded from the study.

\section{Assessment of the cost of the therapy}

Total cost per patient for antidiabetic drugs was calculated. The results were expressed as Mean \pm standard deviation.

\section{Measurement of drug consumption in medicine ward in DDD/1000 patients/day}

Drug consumption in medicine ward was measured in DDD/1000 patients/day. The drugs were classified according to the anatomical therapeutic chemical (ATC) classification system. As per ATC classification system, the medicines are divided into different groups according to the organ or system on which they act and as per their chemical, pharmacological and therapeutic properties. ${ }^{6}$ The DDD/1000 patients/day was calculated using the formula:

Total amount drug used during study period X 1000 DDD (mg/units) X 365 days X total sample size

\section{Statistical analysis}

The data were analysed using graph pad prism version 6.0. Level of significance ( $p$ value) was set at 0.05 . Patient's demographic data were presented as mean \pm standard deviation (SD).

\section{RESULTS}

During the study period, a total of 230 patients with diabetes were admitted to medicine ward. Of these, 222 patients were diagnosed as type 2 diabetes mellitus and 8 as type 1 diabetes mellitus. These results are represented in Figure 1. Out of the 230 patients, 172 (74.7\%) were males and $58(25.2 \%)$ were females. These results are shown in Figure 2. The mean age of patients was $56 \pm 2 \mathrm{SD}$ years with a range between 25 and 80 years. These results are depicted in Figure 3.

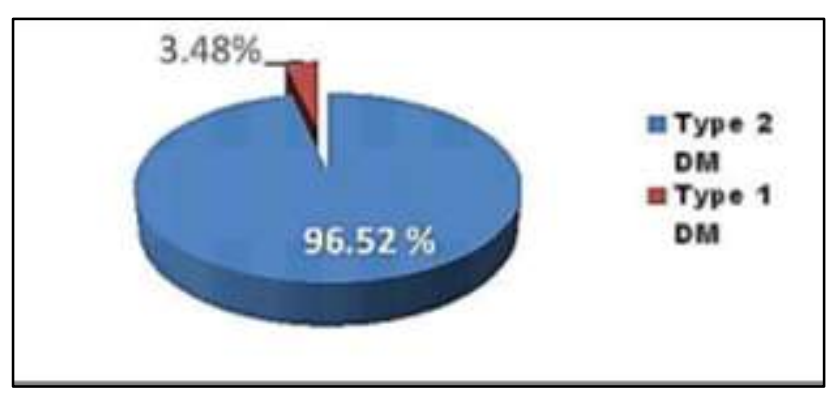

Figure 1: Categorizations of patients of diabetes mellitus based on type.

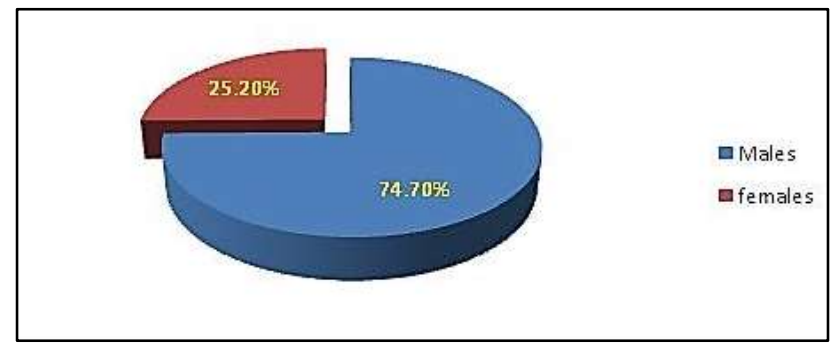

Figure 2: Sex distribution of patients. 
Insulin was prescribed as monotherapy to $82 \%$ patients during hospital stay and to $60 \%$ patients at the time of discharge. The use of insulin at the time of discharge decreased significantly by $22 \%$ (from 82 to $60 \%$, p $<0.05$ ), while use of metformin increased by $6.9 \%$ at the time of discharge $(1.7 \%$ during hospital stay to $8.6 \%$ at the time of discharge, $\mathrm{p}<0.05)$. Utilization pattern of sulfonylureas was $10 \%$ during hospital stay but at the time of discharge it was prescribed to $15 \%$ of the patients. Its utilization thus increased by $5 \%(\mathrm{p}<0.05)$. These results are represented in Figure 4.

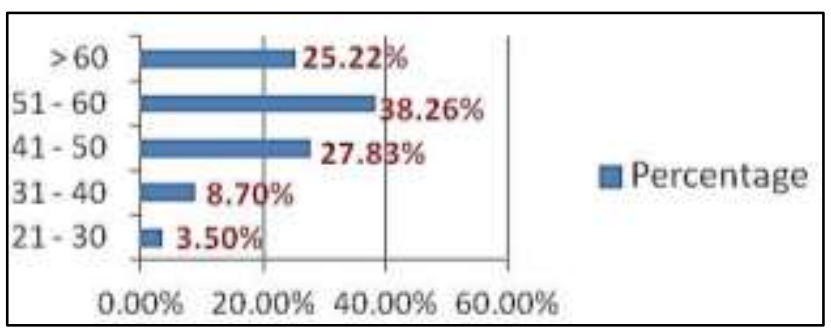

Figure 3: Mean age of patients.

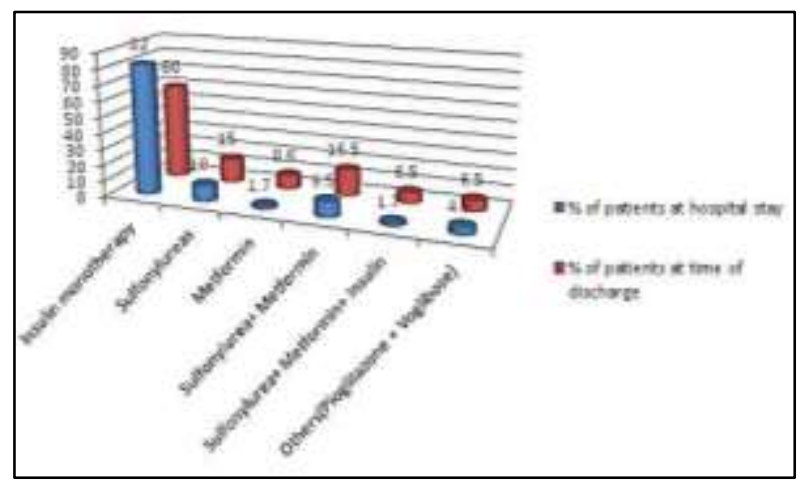

Figure 4: Class of antidiabetics with prescription pattern.

Dual therapy or combination therapy was prescribed less frequently during hospital stay $(9.5 \%)$ than at the time of discharge $(16.5 \%)$. There was a significant $(\mathrm{p}<0.05)$ increase in the prescription of two drugs $(7 \%)$ at the time of discharge and the combination of metformin and a sulfonylurea was prescribed more often at the time of discharge.

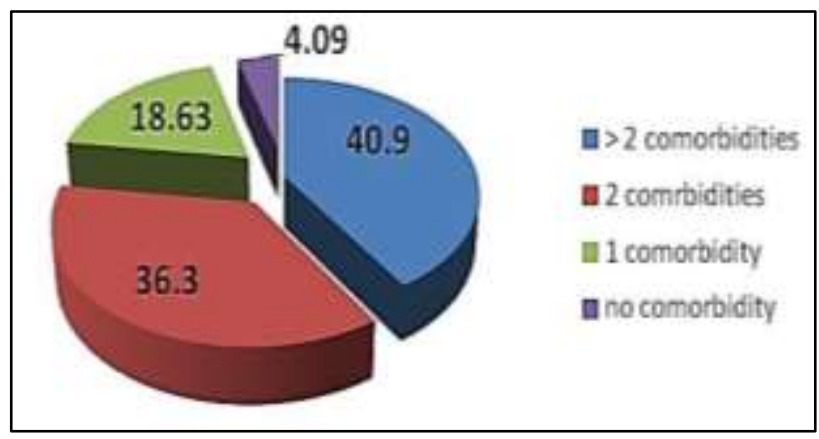

Figure 5: Prevalence of co-morbidities.
Combination of three drugs during hospital stay was found in $1.7 \%$ patients and at the time of discharge in $6.5 \%$ patients. The most prevalent three drug therapy was insulin + metformin + glimepiride. The four drug combination therapy was prescribed only to two patients at the time of discharge. Among glitazones, only pioglitazone was prescribed in combination with the 2 or 3 drugs. $\alpha$-glucosidase inhibitor (voglibose) along with other oral antidiabetic drug was prescribed in $4.3 \%$ of patients.

Co-morbid conditions were found in 220 patients. Among the 220 patients, majority (90) had more than two comorbid conditions in our study, followed by two comorbid conditions (80) and one co morbid condition was present in only 41 patients while 9 were without any comorbidity. These results are represented in Figure 5. The comorbid conditions found were cardiovascular (hypertension, coronary artery disease), nephropathy, neuropathy, sepsis and diabetic foot ulcer etc. Hypertension accounted for $39.1 \%$ of the total comorbidities. These results are depicted in Figure 6.

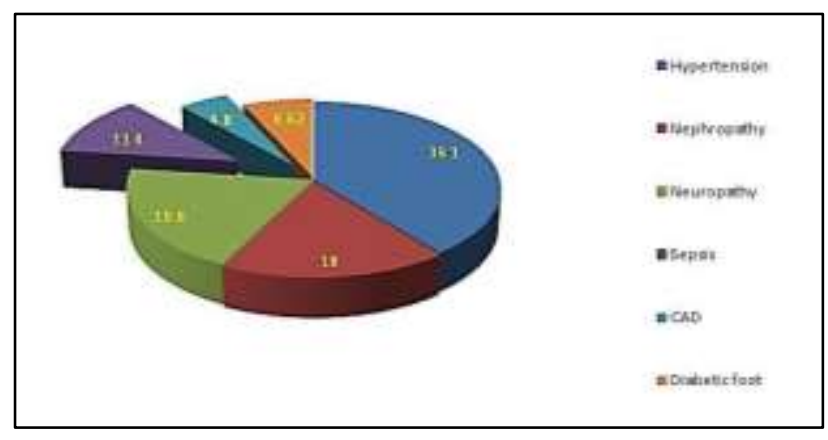

Figure 6: Co-existing illnesses.

\section{Drug consumption and cost analysis}

Drug consumption was calculated in DDD/1000 patients/day. The total insulin consumption was 1.15 and total oral antidiabetic drug consumption at the time of discharge was 14.56 of which metformin (0.24) was used more frequently. The average cost of insulin was rs. 80/patient/month at hospital stay and rs. 88/patient/month at the time of discharge and the average cost of oral antidiabetic drugs was rs.45.66/patient/month at hospital stay and rs. 73.66/patient/month at the time of discharge.

\section{DISCUSSION}

In our study, the mean $\pm \mathrm{SD}$ age of patients was $56 \pm 2 \mathrm{SD}$, a finding similar to that obtained from other study conducted in Ahmedabad (56.8 \pm 10.5 years). ${ }^{7}$ In our study, male predominated the study population $(74.7 \%)$, which was in agreement with the various other studies in India. $^{8-11}$ In our study, hypertension (39.1\%) was commonest co-morbidity observed, which was lower in comparison to other study conducted in Ahmedabad $(70.2 \%)$ and $\operatorname{UAE}(57.8 \%))^{7,12}$ 


\section{Prescribing patterns of antidiabetic agents}

In our study, the most commonly used antidiabetic drug (monotherapy) was insulin during hospital stay and at the time of discharge. During hospital stay, the percentage of patients receiving insulin monotherapy in this study $(82 \%)$ was much higher than that in the previously reported study $(11.5 \%)$ in New Delhi, India. ${ }^{13}$ This could be due to presence of various comorbid conditions like hypertension, nephropathy, infections etc. or presence of uncontrolled diabetes mellitus because of poor knowledge about dietary control or could be due to resistance to oral antidiabetic drugs in patients.

In our study, metformin in combination with a sulfonylurea was the most frequently used two drugs, oral antidiabetic combination prescribed to $9.5 \%$ of patients during hospital stay and to $16.5 \%$ of patients at the time of discharge, which was much lower than that in the previously reported study (50\%) in Ahmedabad, India. ${ }^{7}$ The cause for the same may be due to presence of comorbidities or uncontrolled blood sugar level again. Metformin does not promote weight gain and has beneficial effects on several cardiovascular risk factors. Accordingly, metformin is widely regarded as the drug of choice for most patients with diabetes mellitus. ${ }^{14}$

At present, glibenclamide and glimepiride are the second generation sulfonylurea most widely used in the United States. ${ }^{15}$ In this study, among the sulfonylureas, glimepiride was the most commonly prescribed in combination with metformin. Similar results are found in other study conducted by Sudha et al, there also the most commonly prescribed sulfonylurea was glimepiride. ${ }^{8}$ Among sulfonylureas, selection of glimepiride and glipizide has been recommended by Texas diabetes council because these agents have lower incidence of hypoglycemia than glyburide. ${ }^{15}$

Glimepiride + metformin + pioglitazone + insulin combination was prescribed to 2 patients at the time of discharge in our study, which was much lower than that in the previously conducted study in Kerala, India, where 16 patients were prescribed insulin along with three oral antidiabetic agents. ${ }^{16}$ The reason for lower prescription of the same may be poor compliance with so many drugs, in our study and also the choice of the antidiabetic drugs depends on the type of patients, their current illness, cost factors, as well as the availability of medicine. ${ }^{16}$

$\alpha$-glucosidase inhibitor (voglibose) in combination with other antidiabetic agent was prescribed to $4.3 \%$ of patients in our study, which was lower in comparison to study conducted by Achrya et al, where it had been prescribed to $9.43 \%$ of patients. ${ }^{17}$ The reason for lower prescription of $\alpha$-glucosidase inhibitor, in our study may be, higher cost of it.

\section{Cost of the therapy and drug consumption}

Cost of prescription is very important in chronic disease like diabetes as it may be a major cause for non-adherence to treatment. In our study, the average cost for both insulin and oral antidiabetic agent was under 90 INR/patient/month both at hospital stay and at the time of discharge, which was lower in comparison to study conducted by Acharya et al, where average cost was between 100-400 INR/patient/month. ${ }^{17}$ The reason for low cost of the therapy in our study was because, metformin is given free of cost to the patients and insulin also is supplied at low cost to below poverty line patients in hospital. Another reason for low cost in our study was found to be the prescription of cheapest brand of antidiabetic agents as most of the patients belong to low socio-economic status.

Drug consumption was calculated following the DDD concept to overcome objection against traditional units of measurement of drug consumption. ${ }^{6}$ DDD is defined as the assumed average maintenance dose per day for a drug used for its main indication in adults. It provides a fixed unit of measurement independent of the price and formulations. DDD provide a rough estimate of drug consumption. ${ }^{6}$ The DDD of all type of insulin collectively was $0.134 \mathrm{DDD} / 100$ bed days and for oral antidiabetic agents was 0.028 DDD/100 bed days. DDD calculated in our study was much lower than other study conducted at Mysore, India, where totals antidiabetic drug consumption in the medicine ward was 13.42 DDD/100 bed-days. ${ }^{18}$ This showed a much lower consumption of antidiabetic drugs in our hospital.

Limitation of our study was small sample size, which restricted the generalization of the findings and provision of drugs free of cost and at lower rate to below poverty line people, which restricted the calculation of actual costs of antidiabetic agents.

\section{CONCLUSION}

In our study, males were found to be more affected by type 2 diabetes mellitus than females. Among the various complications, cardiovascular complications caused major threat, of which hypertension was most common. In the study, the prescribing trend was found to be monotherapy with insulin followed by oral antidiabetic agents because of presence of higher incidences of co-morbidities. Among oral antidiabetic agents, metformin along with glimepiride was most commonly used combination. Our study showed, low cost of drugs per prescription as brands with low cost has been prescribed to the patients. So, it is necessary to taken care of quality of drugs.

\section{ACKNOWLEDGEMENTS}

Authors are thankful to Head of the Department and all other unit in charges of Department of General Medicine, 
V. S. S. Institute of Medical Sciences and Research, Burla for their support in conducting the study.

Funding: No funding sources

Conflict of interest: None declared

Ethical approval: Not required

\section{REFERENCES}

1. Sahoo P. National summit on NCDs: Orissa's contribution and initiations appreciated programme to be extended to 4 more districts Bhubaneshwar; 2011. Available

at http://www.odisha.gov.in/samachar/2011/Sep/data/02 -09-2011/NCDs-portal.pdf. Accessed on 25 June 2016.

2. Population of Orissa [Internet] 2015. Available from: www.indiaonlinepages.com/population/orissapopulation.html. Accessed on 25 June 2016.

3. The certificate course in evidence based diabetes management CCEBDM is based on the principles of evidence based medicine. Available at ccebdm.org/news.php.

4. National Programme for prevention and control of Cancer, Diabetes, CVD and Stroke. (NPCDCS) and National Programme for Health Care of Elderly (NPHCE). Progress report of Odisha; 2013:2.

5. Annual report to the people on health. Government of India, Ministry of Health and Family Welfare. 2011:9 Available at http://mohfw.nic.in/WriteReadData/1892s/266972887 36960144509 Annual Report to the People on Health.pdf. Accessed on 25 June 2016.

6. WHO collaborating centre for drug statistics methodology. ATC index with DDDs. Oslo: WHO Collaborating Centre for Drug Statistics Methodology; 2002.

7. Patel B, Oza B, Patel KP, Malhotra SD, Patel VJ. Pattern of antidiabetic drugs use in type-2 diabetic patients in a medicine outpatient clinic of a tertiary care teaching hospital. Int J Basic Clin Pharmacol. 2013;2(4):485-91.

8. Sudha V, Shukla P, Patidar P, Bafna R, Jain S. Prescribing pattern of antidiabetic drugs in Indore
City Hospital Indian. Journal of Pharmaceutical Sciences. 2008;70(5):637-40.

9. Boccuzzi SJ, Wogen J, Fox J, Sung JC, Shah AB, Kim J. Utilization of oral hypoglycemic agents in a drug-insured U.S. population. Diabetes Care. 2004;24(8):1411-5.

10. Johnson JA, Pohar SL, Secnik K. Utilization of diabetes medication and cost of testing supplies in Saskatchewan 2001. BMC Health Serv Res. 2006;6:159.

11. Yurgin N, Secnik K, Lage MJ. Antidiabetic prescriptions and glycemic control in German patients with type 2 diabetes mellitus: a retrospective database study. Clin Ther. 2007;29(2):316-25.

12. Jenny L, Arifulla M, Sreedharan J, Muttappallymyalil J, Das R. Age and gender-based utilization pattern of antidiabetic drugs in Ajman, UAE. Malay $\mathbf{J}$ Pharm Sci. 2012;10(1):79-85.

13. Sultana G, Kapur P, Aqil M, Alam MS, Pillai KK. Drug utilization of oral hypoglycemic agents in a university teaching hospital in India. J Clin Pharm Ther. 2010;35:267-77.

14. Krentz AJ, Bailey CJ. Oral antidiabetic agents: current role in type II diabetes mellitus. Drugs. 2005;65(3):385-411.

15. Dills DG, Schneider J. Clinical evaluation of glimepiride versus glyburide in NIDDM in a doubleblind comparative study. Glimepiride/Glyburide Research Group. Horm Metab Res. 1996;28(9):4269.

16. Kannan, Arshad, Kumar S. A study on drug utilization of oral hypoglycemic agents in type-2 diabetic patients. Asian $\mathrm{J}$ Pharm Clin Res. 2011;4(4):60-4.

17. Acharya KG, Shah KN, Solanki ND, Rana DA. Evaluation of antidiabetic prescription cost and adherence to treatment guidelines: a prospective, cross-sectional study at a tertiary care teaching hospital. J Basic Clin Pharm. 2013;4(4):82-8.

18. Abdi SA, Churi S, Kumar YS. Study of drug utilization pattern of antihyperglycemic agents in a south indian tertiary care teaching hospital. Indian $\mathbf{J}$ Pharmacol. 2012;44(2):210-4.

Cite this article as: Agrawal R, Rath B, Saha K, Mohapatra S. Drug utilization pattern of antidiabetic agents in a tertiary care hospital of western Odisha, India. Int J Basic Clin Pharmacol 2016;5:2222-6. 